Session 3425

\title{
Excellence in Product Design
}

\author{
Jon C. Dixon \\ Adjunct Faculty \\ Programs in Engineering and Technology Management \\ University of St. Thomas \\ St. Paul, Minnesota
}

\begin{abstract}
Industry strives mightily to provide excellent products. No manufacturer is likely to produce excellent designs without understanding what is meant in some way by "excellence". However, it is extremely infrequent to find solid definitions of "design excellence".

The University of St. Thomas (St. Paul, MN) has established a nationally recognized program for graduate level manufacturing engineering education. One of St. Thomas' master's level courses, "Excellence in Product Design", is unique in its approach to defining design excellence.
\end{abstract}

More right-brain than traditional approaches, the course attempts to capture the essence, the root, the genesis of "excellence". Each student attempts to derive a definition of "excellence in design" that may be universally applicable to all consumer products. Selected authors' quotations about excellence help spark lively debate. Discussion includes where in the design process the spark of excellence might originate. Attempts at understanding how such excellence might be fostered in the workplace are undertaken. The roles of industrial design and its potential contributions to design excellence are examined. The concepts of "favorite", "best in class", "quintessential" and "design excellence" are compared and defined. Questions about whether we live in a "claptrap" world are considered.

Topics such as "S-Curve" analysis, closed versus open systems and technology push versus market pull are blended with critiques of DFM/A and QFD to attempt methods of understanding product development methodologies. Ethics in design forms an essential final point of discussion.

This paper outlines the course and illustrates its unique nature.

Proceedings of the 2002 American Society for Engineering Education Annual Conference \& Exposition.

Copyright (c) 2002, American Society for Engineering Education 


\section{University of St. Thomas' Engineering Programs}

The University of St. Thomas is a private university scenically situated high on the bluffs overlooking the Mississippi River in St. Paul, Minnesota. St. Thomas offers an array of outstanding engineering programs within the department of Engineering and Technology Management. The engineering program at St. Thomas may be visited on line at:

\section{- http://www.stthomas.edu/technology/}

An excellent overview of St. Thomas' graduate engineering degrees may be found online at:

- http://www.stthomas.edu/technology/GRAD/ETMOverview.htm

- http://www.stthomas.edu/technology/Programs/MMSEdegree.htm)

- http://www.stthomas.edu/technology/Programs/MSMSdegree.htm

- http://www.stthomas.edu/technology/Programs/TechMgmt.htm.

Design Within Manufacturing

The course is about design but in support of a larger program about manufacturing engineering. This intersection is purposeful. Those who go through our program are often involved in concurrent engineering programs alongside design engineers (and less often, industrial designers). St. Thomas considers engineers seeking master's degrees as tomorrow's leaders of industry. As these engineers advance through their companies and careers, they may well become involved in design, or the management of engineering teams (either design or manufacturing). Further along in their careers, they may be responsible for divisions or entire companies that are producers of goods. To understand the production of excellent products, one must understand the essence of excellence from the perspectives of both producers (from the design and manufacturing vantages) as well as consumers. The course fits well within a manufacturing program because it highlights the importance of design. If the design is poor, average or good at best, manufacturing cannot make it better than it is. If excellent, manufacturing can certainly make a design less than it should be.

\section{$\underline{\text { Excellence in Product Design - A Unique Approach }}$}

I graduated in 1994 from St. Thomas having earned the Master of Manufacturing Systems Engineering (MMSE) degree. I was asked the following year to begin teaching one of the program's courses entitled "Excellence in Product Design". (The course number is MMSE 610). Program director Dr. Ronald Bennett (rjbennett@ stthomas.edu) offered me relative freedom to reframe the course that had traditionally been oriented towards application of DFM/A (design for manufacturing/assembly) and QFD (quality function deployment) principles towards product improvement. I took Dr. Bennett's offer literally, and set about transforming the course into one with an approach that still stands as unique today.

\section{Proceedings of the 2002 American Society for Engineering Education Annual Conference \& Exposition. Copyright (C) 2002, American Society for Engineering Education}


The impetus for reframing this course derived from a systems perspective. The MMSE program (by name and definition) focuses on systems approaches to manufacturing. This course was intended to reflect that systems approach in the realm of design excellence. The majority of students in the MMSE program are engineers working in design, manufacturing and related areas of Minnesota's manufacturing industry. The companies they represent are noted for excellent products and success in their markets. For St. Thomas to offer a course in "Excellence in Product Design", it had to be something beyond what these engineers had learned in their undergraduate programs, and beyond what was being practiced in their respective companies. The substance of the course had to address more than materials usage, reduction of stress raisers, types of threads, methods of calculating forces and best practices. The course, by virtue of its context within the MMSE program and its systems perspective environment, required a step back, a bigger picture, a unique, holistic approach.

It seems impossible to attempt design and production of excellence without having attempted a rigorous definition. The course is therefore focused around the core concept of "excellence". The investigation of theory permits direct examination of the underlying constituents of excellence, and the origins of excellence during product design. Various questions were framed around which the course took shape. What does excellence mean? How can one recognize or even define excellence? How can one hope to produce excellence? From where in the design process do the seeds of excellence grow? It was desired to strike at the very core of excellence in design, trying to understand where excellence comes from, what it means, how it can be defined, how companies encourage or discourage (intentionally and unintentionally) excellence.

The course approach was transformed from atomist or associationist to Gestalt. Rather than focus on synthesizing individual methods of achieving sound design (DFM/A, QFD, etc), the focus was placed on excellence itself. In fact, the standard DFM/A and QFD approaches now come under critique for certain inadequacies in their approaches. The course is now far more right-brain in approach than traditional, left-brain, logical engineering courses. Interestingly, through narrowing the focus to the very origins of excellence, the course is transformed from a narrower to a broader perspective.

Ultimately, what the course provides are contexts of design in the modern world. These contexts include the enduring effect of design on society, the resulting political, social and ecological effects of design and ethical considerations of design. Roles and interactions of various actors (designers, producers, users, consumers, competitors) within the context are considered. The contextual focus of the course creates a situational awareness that what engineers do every day has an impact on the full social and market system within which we all work. That which is designed and produced today affects future generations in manifold and enduring ways. Business risk becomes inseparable from technical risk. Market impact becomes inseparable from social impact.

\section{Proceedings of the 2002 American Society for Engineering Education Annual Conference \& Exposition. Copyright @ 2002, American Society for Engineering Education}




\section{Areas of Focus}

The course focuses on consumer products. Reasons are manifold. Every student is a consumer, but not every student comes from a producer background. The language about the various attributes or drawbacks to designs is common when speaking of everyday consumer items. The large majority of products designed in the world today are consumer items. If one can find suitable definitions and discussions about consumer product excellence, these findings may then be related to other non-consumer products. Students come from many professional backgrounds, including aerospace, medical instruments and armament. It is difficult to achieve common understanding within a class setting when discussing specific products with which others are unfamiliar. Products that are developed under the highly regulated arenas of the FAA (Federal Aviation Administration), the FDA (Food and Drug Administration) or the DOD (Department of Defense) (as examples) lend themselves poorly to inclusion of all members of the class.

The focus on excellence is viewed from both consumer and producer perspectives. Clearly provocative questions arise from this approach. Most of my students believe (particularly at the outset and particularly manufacturing engineers) that essential hallmarks of excellent design must include "ease of manufacture" and "profitability". In playing the devil's advocate, I raise the question of whether or not consumers care at all whether the product they purchase is easy to make or profitable for the producer (or seller). In-depth understanding of these issues adds a great deal to comprehension of critical issues.

\section{Course Methodology}

The course is meant largely as open discussion with the adjunct instructor facilitating the interchange of ideas. Working adult engineers bring a wealth of experience to the classroom. This collective experience, verbally shared in the classroom, brings lively discussion as well as a rich history of experiences.

Extensive use of quotations by famous persons is made, most relating to the concept of excellence. These quotations serve to trigger discourse on the fundamentals of excellence. Opening discussions include a famous quotation by Niccolo Machiavelli ${ }^{1}$ from The Prince:

There are three classes of intellect. One which comprehends by itself; another which appreciates what others comprehend; and a third which neither comprehends by itself nor by the showing of others; the first is the most excellent, the second is good, the third is useless.

Machiavelli's admonition becomes requisite for answering all questions either verbally in class or in writing for assignments. All answers to questions require two-part answers;

\section{Proceedings of the 2002 American Society for Engineering Education Annual Conference \& Exposition. Copyright @ 2002, American Society for Engineering Education}


first "What I believe", and in support, "Why I believe it". In this way, rigor in defending highly subjective arguments becomes part of the skill set refined in the course. The student is encouraged to achieve Machiavelli's first class of intellect. Opinion is transformed into discourse. The student is also encouraged to critique other written literature to see if the author has done the same. This approach serves another function by permitting the instructor to grade on the rigor with which concepts are defended, rather than grading subjective arguments.

The use of quotations about excellence by famous authors raises a great deal of inquiry into the essence of excellence. Quotations from Hessiod to Socrates to Vince Lombardi, all centered on excellence, lay groundwork for discussing excellence in design. The quotations stimulate discussion, encourage right-brain thinking, and provide a catalyst for ideas about potential criteria for design excellence.

\title{
$\underline{\text { Course Objectives }}$
}

A review of the course's five major objectives clearly illustrates the attempts being made to provide a unique approach to considering excellence in design. The regular text illustrates the objectives. The italic text following defines the specific, measurable and attainable learning objective.

I. This course focuses on the key elements that define "excellence in product design". The importance of design excellence is viewed from both consumer and producer perspectives. Examples of good and bad design will be considered.

Each student will, through class discussion, readings, lectures, presentations, guest speakers, a visit to an industrial design house, personal research and book reviews, be able to identify a dramatic variety of criteria that may be considered part and parcel of design excellence. The measure of success is the ability of the student to call upon or reject these criteria in an intellectual way by means of creating his/her own list of well-considered design excellence criteria. This list must be original and rigorously defended.

II. The concepts of "favorite", "best in class", and "quintessence"" are compared with and related to "design excellence".

Each student will learn to define these concepts, understand their appropriate use, and differentiate them from one another. Each student will be able to specify products that meet one or more of these definitions. The measure of success is the ability to utilize these terms appropriately during assignments, discussions and the in-class student presentation.

III. Underlying, constituent criteria for design excellence are explored in depth.

\author{
Proceedings of the 2002 American Society for Engineering Education Annual \\ Conference \& Exposition. \\ Copyright (c) 2002, American Society for Engineering Education
}


Each student will achieve his/her own definition of design excellence, and compare products against that definition. Each student will create a list of criteria that, for that student, defines design excellence for all types of consumer products. The measure of success is the rigor with which the student learns to focus and defend his/her criteria. The application of this knowledge will also be put to the test during the in-class presentation of a product the student claims portrays design excellence.

IV. The role of the industrial designer will be explored.

Each student will visit an industrial design house on a tour, and listen to guest speakers that are industrial designers. The measure of success for explaining the role of industrial design is through writing a paper describing the attributes of industrial design as learned on the tour, and through intelligent inclusion (or exclusion) of industrial design methods while developing the student's list of criteria.

V. Discussions about ethics in design are included.

One text (Discovering Design $\left.{ }^{3}\right)$ deals dramatically with ethics in design. The measure of success is the demonstrated ability of the student to appropriately include ethical dimensions in his/her list of criteria, to verbalize his/her viewpoint in class while discussing the text's authors' perspectives, and to successfully write an ethics papers similar in scope to one of those in Discovering Design.

\section{Grading Opportunities}

There are no exams or quizzes in this course. Grading is based upon collective input from the student in several areas comprised of eight grading opportunities. Assignments below appear in chronological order.

Basic research. The student is asked to research two quotations: "Less is more" (poet Robert Browning) and "Form ever follows function" (architect Louis Henry Sullivan). The student is required to determine who first coined these phrases, their occupation, and what precisely they were writing about when they coined the phrases.

The student is asked also to answer (keeping in mind Machiavelli's admonition) how the quotation applies to design excellence, and whether or not they agree with the statements as they pertain to design of products. The point of the exercise is to encourage the student to consider two basic concepts of excellent design; simplicity and the relationship between form and function. This assignment relates to course objectives I and II, in that the student must understand simple phrases and terms front for complex scenarios, and that defining what is meant by a word or phrase is important.

\section{Proceedings of the 2002 American Society for Engineering Education Annual Conference \& Exposition. Copyright (C) 2002, American Society for Engineering Education}


Written opinion statement. The student is asked early in the course to write an opinion statement. The statement is an attempt at defining the constituent criteria, which when summed, comprise a definition of design excellence. (Clearly every student achieves a unique list. Lists generally contain 10-15 criteria.) The bullet statements contain first the criterion (value, quality, etc.) followed by a definition of what is meant by the criterion. A summation of the criteria is meant to define design excellence. These bullet statements are intended to define the key characteristics of any product that may be considered design excellent, and are intended to apply to any consumer product from a bowling ball to a sailboat. The student must provide a reasonably rigorous defense as to why the summation of the bullet statements or terms can be said to comprise a total definition of design excellence for any given consumer product. Students are asked to think carefully, so their terms, when summed, go beyond definition of merely good or acceptable products, and start to define the essence of true excellence.

This assignment is twice repeated during the course. It is repeated mid-course after the student has heard many other authors' concepts about design and excellence, and after the student has begun reading the book on which their book review will be based. The student has by now acquired a broader understanding of the nuances of excellence, and may alter his or her list of design excellence attributes accordingly, defining the list now with greater rigor and supported by some independent research.

The assignment is repeated one final time near the end of the course. This time the student has been exposed to industrial design concepts, guest speakers and much more classroom discussion. The list must now be defended most rigorously with extensive independent research.

This series of assignments directly address course objective III.

Book review. The student is asked to find and read a book that has something significant to do with design excellence. It may be biographical, autobiographical or historical. The subject must relate in some way to how a person or design theory has contributed significantly to design. The student must illustrate how design excellence is portrayed in the review. Favorite biographical topics include such disparate figures as Frank Lloyd Wright, Raymond Loewy, Enzo Ferrari and Burt Rutan. Other topics include Bauhaus design, beauty in concrete bridge design, and the history of industrial design.

This assignment addresses course objective I.

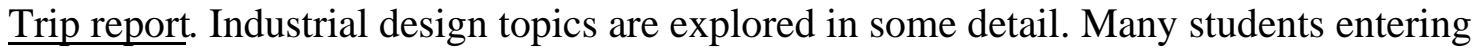
the course have not been exposed to the intention of industrial design. Industrial designers are invited to speak to the class, outlining the intentions of industrial design, and the potential ramifications of using industrial design to advantage. The students are then treated to a full evening in one of the excellent industrial design houses in the Twin Cities. Lively discussion about projects undertaken by the company and the theory about

\footnotetext{
Proceedings of the 2002 American Society for Engineering Education Annual Conference \& Exposition. Copyright (O 2002, American Society for Engineering Education
} 
how the company influences design excellence are typical results of the evening. The student must hand in a single page written trip report describing his or her experiences, highlighting how industrial designers feel they do contribute to design excellence.

This assignment directly addresses course objective IV.

Class presentation. The student is required to bring to class and demonstrate one consumer product that the student believes portrays that student's full complement of design excellence criteria. The student is given approximately fifteen minutes to introduce the product, demonstrate it, tell about its market, its manufacturer, its competitors and what makes it an excellent design. This is generally a very entertaining exercise that encourages creative thought and innovative presentations.

All course objectives are intended to be addressed by this presentation.

$\underline{\text { Research paper on ethics in design. Four authors of the Discovering Design }}{ }^{3}$ text discuss various aspects of design ethics. The student is asked to critically analyze the works of Winner, Mitcham, Fry and Manzini. Each author's perspectives are noted. The student then illustrates how the authors agree and where they differ. The second part of the assignment is for the student to write his or her own paper on ethics in design, selecting from any number of potential areas of ethical focus.

This assignment directly addresses course objective V.

\section{Course Outline: Beyond Course Objectives}

While the course is never precisely the same twice in a row, unique issues not directly related to the five course objectives are always discussed.

- The fundamental concept of excellence is approached using quotations from historical figures. Understanding the true essence of excellence in all endeavors strikes at the heart of the course. It is essential the student understand that excellence stems from a critical, inspirational spark. That spark may or may not be sustained depending largely on the environment provided for that spark. What is most important however is that the student realize that excellent products stem from some original spark, and that the vast majority of today's corporate environments do little indeed to sustain or nourish that spark. Moreover, it is nearly impossible to produce excellence if little to no attempt is made to understand it.

- A review of numerous design flow charts is undertaken. Charts from manifold sources indicate how the management of many companies perceives the design process and how it is generally managed. Actual design process flow charts ranging from straightforward to highly complex, four-page affairs are examined. The students are challenged to determine why careful inspection of the processes does not

\footnotetext{
Proceedings of the 2002 American Society for Engineering Education Annual Conference \& Exposition. Copyright @ 2002, American Society for Engineering Education
} 
highlight the time or place where the critical, inspirational spark of excellence might take place. The fact that the design process is so heavily managed in many cases highlights the inherent juxtaposition and contradiction of "managing the design process", in reality a highly creative, artistic and right-brain endeavor.

- S-Curve analysis is a special focal point of the course. Describing the life of a product from $R \& D$ through manufacturing ramp-up to maturity by use of an S-shaped curve is not new. However, the course uses this type of analysis as a springboard to highlight related topics. Examples include judicious balance between manufacturing and research investment, and how research strategies may be guided by proper $\mathrm{S}$ Curve analysis.

- Companies that permit mature products to linger too long on the mature end of the SCurve, or whose cultures become too risk-averse to wander far from the market pull approach of product development, may become overly confident. This overconfidence opens the company up to what Richard Foster ${ }^{4}$, in his book Innovation: The Attacker's Advantage, calls the "attacker's advantage". Excessive reliance on mature product offerings, mild variations on a theme rather than really new products, and malaise regarding serving customer needs (as opposed to competing with competitors) open some companies to attack from competitors that are not hindered by this dangerous and nonproductive momentum.

- The inherent limits of technologies, and how those limits may be used to gauge new product development strategies are investigated. Every product is comprised of inherent and enabling technologies. These technologies may be production technologies, material technologies or physics limits. I describe these as "constituent" technologies. But every technology has limits. The use of limitist theory (Foster") is explored as a means of studying constituent technologies to understand their finite limits, and how those finite limits affect the ability to continue developing current product lines. Understanding the finite limits of a product's constituent technologies tells the producer much about how and when to replace one's own offerings with something new. Such an analysis can help guide R\&D strategies.

- Phenotype to genotype ratios are also discussed as a means of gauging the type of competition in a particular market. Discussion is based on Morello's paper in Discovering Design ${ }^{3}$. A phenotype may be said, in the context of product design, to be a derivative product, one based on something that has come before, an evolution. A genotype, conversely, is something unique, entirely different and fresh. Certainly not all products should be genotypes, but a high phenotype to genotype ratio in a particular market may well be an indicator of prime opportunity to remake that market. It is one symptom that the "attacker" may have an advantage.

- Market pull versus technology push approaches to product development are engaged. The relative merits and drawbacks of both approaches are discussed in detail. The

\section{Proceedings of the 2002 American Society for Engineering Education Annual Conference \& Exposition. Copyright (c) 2002, American Society for Engineering Education}


potential, perhaps a better word is ability, to develop genotype versus phenotype products in companies whose management style is strongly market pull oriented is discussed. Management comfort, style and culture as they relate to types of product development strategies are explored.

- The students are asked to consider whether we live in a "claptrap" age. Several of the authors' works in the course describe the transition from the age of craftsmanship, through the industrial revolution to today's mass manufacturing as one of abandonment of soul for volume. Many authors describe the mass production of cheap, heartless, soulless, throw-away products that may be described as "claptrap". Considerable discussion is given to whether the students agree with this description or not.

- Corporate environments are highlighted. Many corporate cultures stultify creativity by enforcing rigid and drab environments, while on the other hand demanding creative input and innovation. The environments that enable or hamper design excellence are discussed and role-played to some degree. (See discussion below on Cliff Havener's textbook.)

- Margaret Thorpe, principal of Venture Catalyst in St. Paul, Minnesota, is a guest speaker. Thorpe is a designer of market and business development strategies. Thorpe discusses "business as an ecosystem" with the class. An ecosystem, including a business ecosystem, is a dynamic, open, self-organizing system whereby exchange of value for mutual benefit among the constituents in a quest for survival is sustained. The impact on design excellence stems from understanding the concepts of "exchange of value" and "mutual benefit", and how designs may or may not contribute to these parts of the system of enterprise.

\section{$\underline{\text { Texts }}$}

I have found only two books suitably creative to serve as textbooks for this course. I have simply not found a good text that focuses on the essence of "excellence in design" without reverting to design mechanics on one hand or the more art-related aspects of design on the other. These two texts are, however, fine adjuncts to the coursework.

The first is Discovering Design ${ }^{3}$. The book is a compilation of papers by various authors including professors of design, design history, philosophy and political science. Each author touches on the essence of design in a unique and meaningful way. Topics of discussion by these authors are rich and full of texture. Contributing authors and topics include:

- Victor Margolin

The concepts of "product milieu" and "product web" and human interactions with them

Proceedings of the 2002 American Society for Engineering Education Annual Conference \& Exposition.

Copyright (C) 2002, American Society for Engineering Education 
What is design and who are designers?

The design of action and products

The influence of products on action

- Gianfranco Zaccai

Effects of the industrial revolution on design

The forced compromise between craftsmanship and industrial society

The expanding role of modern design

Aesthetics redefined

Design for the senses and kinesthetics

- Augusto Morello

Concepts of users versus consumers

Concepts of genotypes and phenotypes in design

Perils of too high a phenotype/genotype ratio

Gestalt perspectives in design

"Analytic" versus "synthetic" design

- Langdon Winner

Shared territory of politics and design

Political ergonomics

- Carl Mitcham

The social impact of modern design

Ethics of design

- Tony Fry

The sacred, and the community

Craft and care

Design for total economy and community

- Ezio Manzini

The postindustrial metropolis

Limits

The "culture of doing"

The ecology of artificial things

The concept of a "garden of objects"

The second text is Cliff Havener's ${ }^{5}$ Meaning: The Secret of Being Alive. Havener is the founder of Growth Resources Group, Inc. in Scandia, Minnesota. (Havener's work may be referenced at www.forseekers.com. ) Havener also joins each course a guest speaker.

Proceedings of the 2002 American Society for Engineering Education Annual Conference \& Exposition.

Copyright (c) 2002, American Society for Engineering Education 
In Meaning, Havener defines closed corporate systems (those that focus in upon themselves) and open corporate systems (systems which are in touch with and interact creatively with the external world). The former are so involved with the form of what they are presently doing, that they fail to understand the world is changing and that form is less important that the essential reason for the company and its offerings. Their focus is inward. The latter are alive, responsive and tuned in to the external environments within which they operate. Their focus is outward. Havener goes further to illustrate how open companies continually rejuvenate or remake themselves by responding to the world around them in a third stage Havener calls integrative. Havener's insights contribute to the course by illustrating how certain corporations systematically foster innovation, creative thought and excellence while others equally systematically hamper and neglect them just by the closed nature of their businesses. Students are encouraged to critique their own companies with regard to potential for excellence.

\section{$\underline{\text { Summary }}$}

The University of St. Thomas' course "Excellence in Product Design" is a highly unique approach to design, particularly as it is wrapped within the framework of a master's degree aimed at modern manufacturing systems. The core course philosophy is to utilize Machiavelli's first class of intellect to define excellence as it pertains to consumer products. Armed with such a definition (even if not perfect), the user may then have a hope of affecting the production of excellence, not claptrap.

\section{Bibliography}

1. Machiavelli, Niccolo (1532). The Prince.

2. Cornfeld, Betty \& Edwards, Owen (1983). Quintessence: The Quality of Having "It". New York, NY: Crown Publishers, a Division of Random House, Inc. ISBN: 1-57912-150-0.

3. Buchanan, Richard \& Margolin, Victor (Eds.) (1995). Discovering Design: Explorations in Design Studies. Chicago: University of Chicago Press. ISBN: 0-226-07814-0.

4. Foster, Richard N. (1986). Innovation: The Attacker's Advantage. New York, NY: Summit Books, a Division of Simon \& Schuster, Inc. ISBN: 0-671-62250-1.

5. Havener, Cliff (1999). Meaning: The Secret of Being Alive. Edina, MN: Beaver's Pond Press, Inc. ISBN: 1-890676-34-9.

\section{JON C. DIXON}

Jon Dixon is an adjunct faculty in the Graduate Programs in Engineering and Technology Management at the University of St. Thomas in St. Paul, Minnesota. Mr. Dixon received his Bachelor of Aerospace

Proceedings of the 2002 American Society for Engineering Education Annual Conference \& Exposition. Copyright (C) 2002, American Society for Engineering Education 
Engineering and Mechanics degree at the University of Minnesota, and his Master of Manufacturing Systems Engineering degree at the University of St. Thomas. He is presently seeking his second master's degree in Technology Management, and is a doctoral student in Educational Leadership at the University of St. Thomas. Mr. Dixon has 20 years experience in industry as an engineering manager with the Goodrich Corporation. 